\title{
THE REORGANIZATION OF ROOT ANATOMY AND ULTRASTRUCTURE OF SYNCYTIAL CELLS IN TOMATO (LYCOPERSICON ESCULENTUM MILL.) INFECTED WITH POTATO CYST NEMATODE (GLOBODERA ROSTOCHIENSIS WOLL.)
}

\author{
SYLWIA FUDALI, WŁADYSŁAW GOLINOWSKI \\ Department of Botany, Warsaw Agricultural University \\ Nowoursynowska 159, Building 37, 02-776 Warszawa, Poland \\ e-mail: sylwia_fudali@sggw.pl
}

(Received: May 17, 2006. Accepted: June 4, 2007)

\begin{abstract}
The sequence of anatomical and ultrastructural events leading to the syncytium development in tomato roots infected with Globodera rostochiensis was examined. The syncytia were preferentially induced in cortical or pericyclic cells in the elongation zone of root. They developed towards the vascular cylinder by incorporation of new cells via local cell wall breakdown. After surrounding primary phloem bundle and reaching xylem tracheary elements syncytia spread along vascular cylinder. Roots in primary state of growth seemed to be the best place for syncytium induction as syncytia formed in the zone of secondary growth were less hypertrophied. At the ultrastructural level syncytial elements were characterized by strong hypertrophy, breakdown of central vacuole, increased volume of cytoplasm, proliferation of organelles, and enlargement of nuclei. On the syncytial wall adjoining vessels the cell wall ingrowths were formed, while the syncytial walls at interface of phloem were considerably thickened. They lacked of functional plasmodesmata and did not form any ingrowths. Using immunofluorescentlabelling and immunogold-labelling methods tomato expansin 5 protein was localized in nematode infected roots. The distribution of LeEXP A5 was restricted only to the walls of syncytia. The protein distribution pattern indicated that LeEXP A5 could mediates cell wall expansion during hypertrophy of syncytial elements.
\end{abstract}

KEY WORDS: cell hypertrophy, expansin, susceptible interaction, syncytium development.

\section{INTRODUCTION}

Globodera rostochiensis is a quarantine pest which causes substantial loses to European agriculture (Haydock and Evans 1998). This obligatory and sedentary endoparasite belongs to cyst nematodes and infects roots of some economically important Solanaceous plants including potato and tomato. Cyst nematodes induce profound changes in the developmental programme of root cells, leading to the formation of the multinucleate and metabolically active feeding site called syncytium. The syncytium reveals features of transfer cells and is a sole source of nutrients for developing nematode (Jones and Northcote 1972). It develops from one single cell selected by the infective juvenile (J2) of the nematode (Wyss 1992). Syncytium formation includes two main processes: incorporation of new cells by local dissolution of cell wall and the hypertrophy of incorporated elements. Organization of apoplastic and symplastic components of cells incorporated to the syncytium is dramatically changed. The typical features of syncytial elements are dense cytoplasm, enlarged nuclei, proliferation of organelles including plastids, mitochondria and endoplasmic reticulum, numerous small vacuoles and formation of wall ingrowths on the walls adjacent to xylem tracheary elements (Golinowski et al. 1996). After syncytium induction the juvenile passes through three moults: to J3, J4 and finally to adult developmental stage.

It is generally accepted, that nematode via its secretions manipulates with plant gene expression what results in the reprogramming of root cell differentiation. The main efforts to understand the interaction between parasite and its host are identification and characterization of nematode secretions (Vanholme et al. 2004) and identification of plant genes differentially expressed in syncytia (Gheysen and Fenoll 2002).

During syncytium development plant cell walls undergo extensive rearrangements, like localized dissolution during cell wall opening formation, expansion during hypertrophy of syncytial elements, synthesis of wall ingrowths and a general thickening. Due to the complexity and synchronization of these processes, it has been postulated that genes of plant origin are responsible for cell wall modifications accompanying syncytium development (Jones 1981).

Expansin superfamily of plant genes encodes extracellular proteins that have unique ability to induce cell wall loosening, probably by disruption of non-covalent bonds be- 
tween cell wall matrix polysaccharides and cellulose microfibrils (McQueen-Mason and Cosgrove 1994). They are implicated in many developmental processes where cell wall modification occurs: from cell expansion during plant growth (Fleming at al. 1999) to cell wall dissolution during fruit ripening (Rose et al. 1997). Recent studies have demonstrated, that tomato expansin gene LeEXP A5 is up-regulated in nematode infected tomato roots and based on in situ transcript localization and immunolocalization study it has been proposed that LeEXP A5 plays a role in the hypertrophy of syncytial elements (Fudali et al. 2004).

This paper describes anatomical and ultrastructural modifications during induction and development of syncytia induced by $G$. rostochiensis in susceptible tomato roots. To provide additional information of possible function of expansin 5 in syncytium development supplementary immunolocalization studies of LeEXP A5 are presented in the context of detailed histological and ultrastructural analysis.

\section{MATERIAL AND METHODS}

Tomato roots infected with nematodes used in all experiments were obtained from axenic culture. Tomato seeds (Lycopersicon esculentum Mill., cv. Money Maker) were surface-sterilized in $70 \%(\mathrm{v} / \mathrm{v})$ ethanol for $3 \mathrm{~min}, 30 \%$ $(\mathrm{v} / \mathrm{v})$ commercial bleach for $10 \mathrm{~min}$ and rinsed three times with sterile water. Seeds were germinated on Petri dishes containing $1.2 \%(\mathrm{w} / \mathrm{v})$ agar at $20^{\circ} \mathrm{C}$ in the darkness. After 5 days seedlings were transferred into Petri plates with medium containing $3.2 \mathrm{~g} / \mathrm{l}$ Gamborg's B-5 Basal Medium with Minimal Organics (Sigma) supplemented with $2 \%$ $(\mathrm{w} / \mathrm{v})$ sucrose and $1.5 \%(\mathrm{w} / \mathrm{v})$ agar $(\mathrm{pH}$ 6.2). Plants were grown at $18^{\circ} \mathrm{C}$ at $16 / 8 \mathrm{~h}$ light/darkness photoperiod. After 10 days aerial parts of plants were cut off and each root system was inoculated with about 500 freshly hatched J2 juveniles under sterile conditions. The culture of Globodera rostochiensis Woll. (patotype Ro1 Mirenbos, provided by The Laboratory of Nematology, Wageningen University, The Netherlands) and plant inoculation was carried out according to Goverse et al. (2000). After inoculation plates were kept at $18^{\circ} \mathrm{C}$ in the darkness. Tomato roots were observed in vivo using binocular to determinate the exact time of the syncytium induction. Tomato root pieces containing syncytia of 1-5 dpi (days post induction, corresponding to the J2 nematode developmental stage) and 10-14 dpi (corresponding to the late $\mathrm{J} 3$ nematode developmental stage) were excised, fixed and embedded for ultrastructural microscopic observation and immunolocalization studies, separately.

\section{Structural studies}

Samples were pre-fixed for $2 \mathrm{~h}$ in $2 \%(\mathrm{w} / \mathrm{v})$ paraformaldehyde and $2 \%(\mathrm{w} / \mathrm{v})$ glutaraldehyde in $0.05 \mathrm{M}$ sodium cacodylate buffer ( $\mathrm{pH} 7.2$ ) and post-fixed for $2 \mathrm{~h}$ in $2 \%(\mathrm{w} / \mathrm{v})$ osmium tetroxide $\mathrm{OsO}_{4}$ at $4^{\circ} \mathrm{C}$. After dehydration in a graded ethanol series and propylene oxide samples were embedded in epon resin. Series of transverse sections (2.0 $\mu \mathrm{m}$ thick) were cut on dry glass knives using a Leica RM 2165 microtome and stained with $1 \%$ (w/v) Crystal Violet for $30 \mathrm{~s}$. The anatomy of syncytia was analyzed under light microscope Olympus AX 70 "PROVIS" equipped with digital camera Olympus DP50 and documented using Analy-
SIS software. The ultrathin sections $(90-110 \mathrm{~nm})$ were cut with the diamond knife using ultramicrotome Ultracut E (Reichert-Jung), stained with uranyl acetate and lead citrate and examined under electron microscope FEI 268D "Morgagni". For photographic documentation digital camera SIS Morada and iTEM software were used.

\section{Immunofluorescent-labelling}

Polyclonal anti-EXP A5 antibodies were raised in rabbit against 14 aminoacid fragment from C-terminus of the expansin 5 protein. The antibodies were purified using Protein A Antibody Purification Kit (Sigma) according to the manufacturer's procedure and their specificity was verified in Western Blot analysis. Samples were fixed in $4 \%(\mathrm{w} / \mathrm{v})$ paraformaldehyde in $50 \mathrm{mM}$ PIPES buffer ( $\mathrm{pH} 6.9)$ for $2 \mathrm{~h}$, dehydrated in ethanol and embedded in BMM resin $(80 \%$ $(\mathrm{v} / \mathrm{v})$ buthylmethacrylate, $20 \%(\mathrm{v} / \mathrm{v})$ methylmethacrylate, $0.5 \%(\mathrm{w} / \mathrm{v})$ benzoilethylether, $10 \mathrm{mM}$ DTT). The semi-thin sections were adhered to Silane-Prep Slides (Sigma) at $45^{\circ} \mathrm{C}$ on a slide warmer. BMM resin was removed with acetone and unspecific binding sites were blocked with $3 \%$ BSA in TBS for $1 \mathrm{~h}$. Then, slides were incubated with antiEXP A5 antibody diluted to 1:100 in TBS for $1 \mathrm{~h}$. Slides were rinsed with TBS and incubated with secondary goat anti-rabbit antibody conjugated with Alexa Fluor 488 (Molecular Probes) diluted to $1: 1000$ in $1 \%(\mathrm{w} / \mathrm{v})$ non-fat dry milk in TBS for $1 \mathrm{~h}$. Slides were mounted using ImmunoFluore Mounting Medium (ICN Biomedicals) and were observed under Olympus AX 70 "PROVIS" microscope equipped with U-M61002 filter set. The results were documented as described for anatomical examination.

\section{Immunogold-labelling}

The material was fixed and dehydrated as described for immunofluorescent labelling and subsequently infiltrated in a series of ethanol: LR-white mixtures and embedded. Samples (90-110 nm thick) were cut on Utracut E (Reichert-Jung) ultramicrotome and transferred onto formvar coated nickel grids. Sections were blocked in $2 \%(\mathrm{w} / \mathrm{v})$ BSA in TBS for $1 \mathrm{~h}$ and subsequently incubated in diluted 1:100 anti-EXP A5 antibody in TBS. After washing with TBS buffer and incubation in a secondary mouse anti-rabbit gold-conjugated antibody (10 nm grains) diluted 1:50 with TBS the grids were washed with water. Sections were counterstained with uranyl acetate and examined under transmission electron microscope as described for ultrastructural analysis of syncytia.

\section{RESULTS}

\section{Induction of syncytium}

The infective juveniles of Globodera rostochiensis (J2) invaded the roots preferentially in the root elongation zone just behind the root tip. Then, J2s migrated in the root cortex along the vascular cylinder. After selection of initial syncytial cell (ISC) syncytium started to develop by incorporation of neighbouring cells. As a result a large volume of the root was occupied by multinucleate nematode feeding structure consisting of hypertrophied root cells. Figures 1-12 present serial cross sections of three different roots containing syncytia: 5 dpi (days post induction) syncytia (Figs 1-4), 14 dpi syncytia induced in the root of primary 

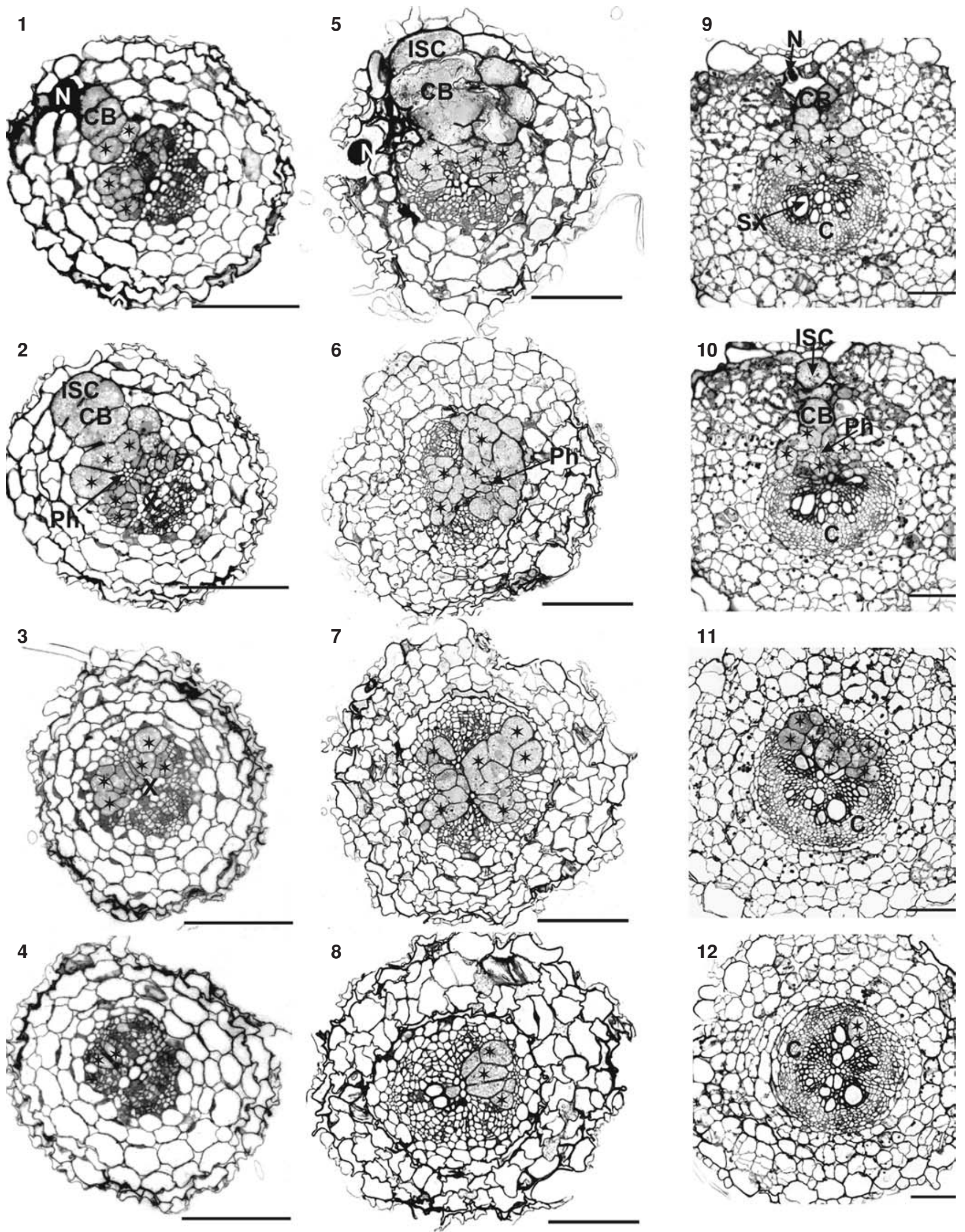

Figs 1-12. Cross sections of the tomato roots containing syncytia induced in the cortex.

Figs 1-4. Sections through syncytium induced in the root being in the primary state of growth (5 dpi) corresponding to J2 developmental stage. Figs 5-8. Sections through syncytium induced in the root being in the primary state of growth (14 dpi) corresponding to the J3 developmental stage. Figs $9-12$. Sections through syncytium induced in the root being in the secondary state of growth (14 dpi), associated with J3 juvenile.

The syncytia were serially cut, but only sections from one halves of them located in one direction from the nematode head are presented. Bars 100 um. Abbreviations: C - cambium; CB - "cortex bridge"; ISC - initial syncytial cell; N - nematode; Ph - phloem bundle; SX - secondary xylem; X - xylem tracheary elements; syncytial elements derived from the pericycle and vascular parenchyma are marked with asterisks. 
state of growth (Figs 5-8) or 14 dpi syncytia induced in the root of secondary state of growth (Figs 9-12).

In most cases, syncytia were induced at the opposite site of the phloem bundle. Usually cortical cells (Figs 2 and 5) or rarely pericyclic cells were selected by juveniles as ISC. Accidentally, the $\mathrm{J} 2 \mathrm{~s}$ invaded roots in the zone of lateral roots formation, at places where secondary thickening had already been initiated (Fig. 10).

In the wall of ISC, at the place where nematode stylet was inserted a feeding plug was formed and nematode secretions were released into this osmophilic structure (Fig. 13). In the protoplast of the ISC close to the feeding plug electrondense material and faint membranous structures, formed probably by nematode secretions, were present. The protoplast of ISC underwent numerous alterations and the first wall openings were already formed. In the close vicinity of nematode head the cytoplasm was condensed and contained many organelles, including endoplasmic reticulum, mitochondria, plastids with starch grains and dictyosomes. The region of the central vacuole was occupied by granular material and numerous vesicles (Fig. 15). In addition, a feeding tube was already present in the condensed cytoplasm of the ISC, indicating that the nematode had started to withdrawn nutrients from its host. Feeding tube was associated with cisternae of endoplasmic reticulum and with faint membranous structures (Fig. 15).

The first cell wall openings were formed at the site of existing plasmodesmata (Fig. 14). In the region of wall opening formation the plasmodesmata were gradually widened. In their vicinity paramural bodies (membrane invaginations containing aggregates of many small vesicles) were formed and cytoplasm contained many cisternae of
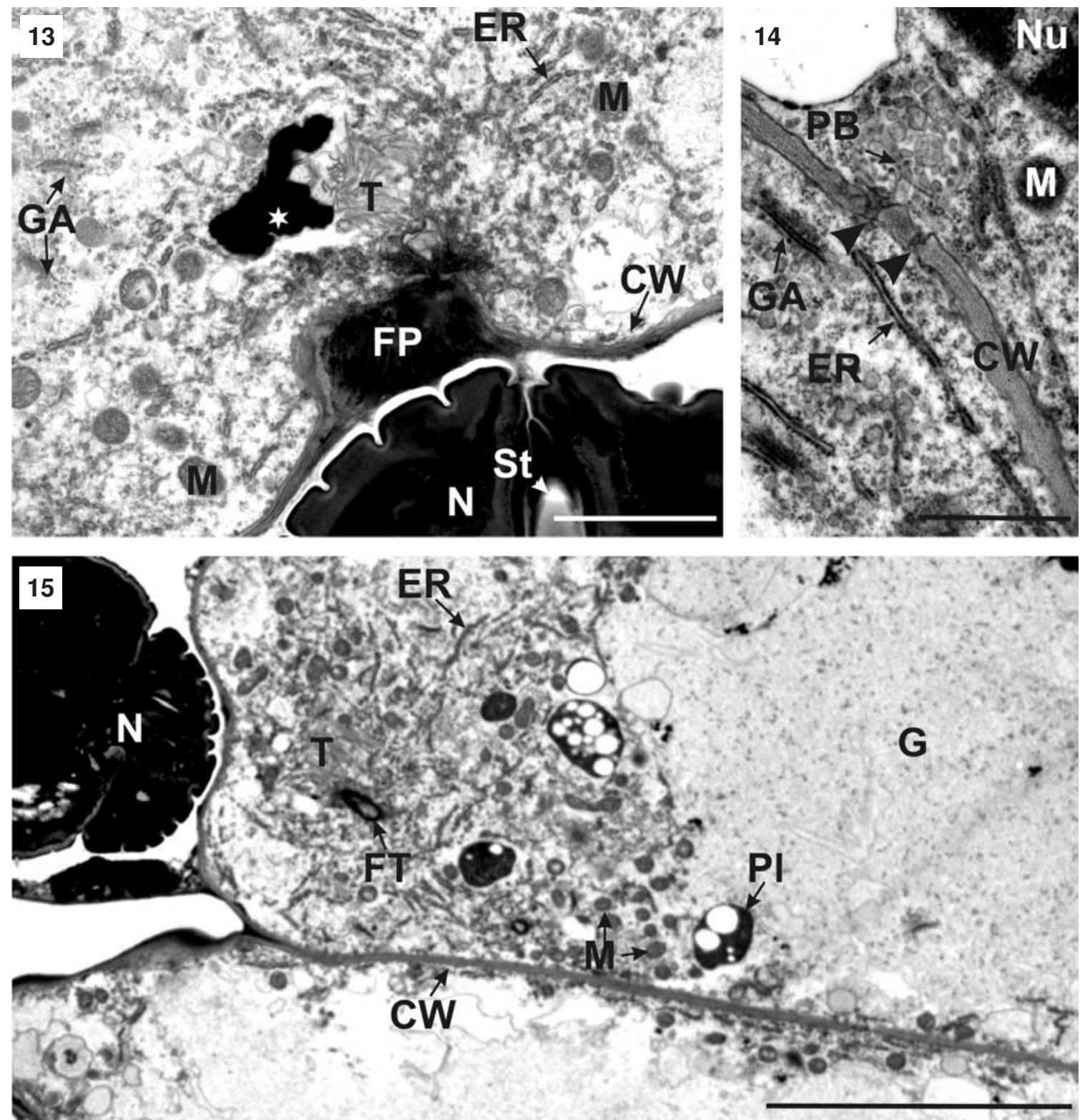

Figs 13-15. Ultrastructure of the initial syncyncytial cell (ISC) in infected tomato root (1 dpi).

Fig. 13. Fragment of the ISC with feeding plug (FP) present in the cell wall of the ISC. Close to the feeding plug osmophilic material (asterisk) and tubular structures (T) are formed. CW - cell wall; ER - endoplasmic reticulum; GA - Golgi Apparatus; $\mathrm{M}$ - mitochondrion; N - nematode; St - stylet. Bar 2 um. Fig. 14. The first cell wall openings formed in the wall of ISC with involvement of existing plasmodesmata (arrow heads). CW - cell wall; ER - endoplasmic reticulum; GA - Golgi Apparatus; M - mitochondrion; Nu - nucleus; PB - paramural body. Bar $1 \mu \mathrm{m}$. Fig. 15 . Fragment of the protoplast of ISC. The cytoplasm of ISC close to the nematode head (N) is dense. CW - cell wall; ER - cisternae of endoplasmic reticulum; FT - feeding tube; G - granular material in the region of central vacuole; $\mathrm{M}$ - mitochondrion; Pl - plastids; T - tubular structures. Bar $10 \mu \mathrm{m}$. 
rough endoplasmic reticulum, mitochondria and Golgi Apparatuses. The wall openings were frequently formed in close vicinity to each other with involvement of neighbouring plasmodesmata.

\section{Development of syncytium}

Syncytium induced in the cortex developed centripetally towards vascular cylinder by incorporation of a row of cortex cells (Figs 1 and 2). Successive wall openings were formed and widened between neighbouring cells. Through the wall gaps protoplasts of adjacent cells fused resulting in multinucleate syncytium. The cells incorporated into the syncytium become strongly hypertrophied and contained dense cytoplasm (Figs 1-4). The syncytial elements connecting ISC with vascular cylinder are called "cortex bridge" (Sembdner 1963). When pericyclic cells were fused with the "cortex bridge" and syncytium reached a phloem bundle, it enlarged further by incorporation of undifferentiated parenchymatous cells and enclosed phloem bundle. Then, new cells of stelar parenchyma were incorporated into the syncytium and it reached contact to xylem tracheary elements (Fig. 2). At this point, syncytium started to expand longitudinally basipetally and acropetally, along conductive tissues by successive incorporation of vascular parenchyma cells (Figs 3 and 4). As a result, the syncytium at $5 \mathrm{dpi}$, corresponding to nematode $\mathrm{J} 2$ stage, consisted of two well distinguishable parts: the older part located next to the nematode head and the recently incorporated part located distally from the ISC. The part of syncytium located next to the nematode head was composed of cortical, pericyclic and parenchymatic cells, while distal part of syncytium located away from the ISC was composed of vascular parenchymatic cells only. The most distal parts of syncytium consisted of only few weakly hypertrophied parenchymatic cells (Fig. 4).

In older developmental stage (syncytium associated with the J3 nematode stage), the syncytium spread mostly longitudinally, equally in acropetal and basipetal directions, along conductive tissues by incorporation of new vascular parenchyma cells. It proliferated by incorporation of new cells via cell wall openings formation and enlargement of incorporated cells. Both, the size and cellular composition of syncytium at 14 dpi (corresponding to the J3 developmental stage) correlated with the localization of the ISC within the root. The most hypertrophied syncytia were those induced in the cortex in roots being in the primary state of growth (Figs 5-8). The largest syncytial elements with the widest cell wall openings were present among cells incorporated at the beginning of syncytium development, which were derived from cortex and pericycle (Fig. 5). The large part of volume of such syncytia was formed by hypertrophied parenchymatous cells located along the vascular cylinder over a long distance (up to $1010 \mu \mathrm{m}$ from ISC). If metaxylem vessels have not yet been differentiated they were incorporated into the syncytium (Figs 6 and 7) and syncytium occupied both sides of primary xylem pole. Although pericyclic and vascular parenchyma cells incorporated into the syncytium were smaller in size than the cells of the "cortex bridge", it seems that the fold of hypertrophy was similar in both cases or even lower in the latter case. On the cross sections the diameter of syncytial cells derived from cortex was approximately 1.5-2.0 times greater than the diameter of not affected cortical cells (Fig. 5), while the diameter of syncytial elements derived from the vascular parenchyma was increased up to 5.0 times, when compared with parenchymatous cells of vascular cylinder not incorporated into syncytium (Fig. 8). The parenchymatic cells of vascular cylinder neighboring with distal syncytial elements divided.

The syncytium induced in the cortex in the roots where the process of secondary growth has already been initiated was less proliferated (Figs 9-12). The "cortex bridge" was composed only of a single row of cortical cells localized behind the primary phloem bundle. The part of syncytium bordering to the "cortex bridge" was composed of few pericyclic cells that surrounded the phloem bundle and reached the primary xylem elements. The oldest part of syncytium occupied a half of the stele at the level of the ISC. In the part of the root containing syncytial elements located next to the nematode head the secondary growth of the root was impeded (Figs 9 and 10). The tracheary elements of secondary xylem differentiated solely at the opposite site of primary xylem bundles where syncytium did not develop. The cambium cells reached the syncytium elements, but they did not surround them and did not form a continuous ring. The part of syncytium situated in some distance from nematode head was composed of vascular parenchyma cells only (Fig. 11). The hypertrophy of cells derived from vascular parenchyma was not hampered. In this region of root the cambium reached syncytium edges located in the stele. The parenchymatic and pericyclic cells not incorporated into the syncytium divided. The most distal part of syncytium was composed of several (one to three) strongly hypertrophied parenchymatic cells located within the vascular cylinder (Fig. 12). The differentiated cambial cells almost surrounded the most distal syncytial elements and secondary tracheary elements development in their vicinity became more symmetric.

\section{The ultrastructure of developing syncytium}

On establishment of the syncytium (3 dpi) cells incorporated into it had a different protoplast organization. In general, the characteristic features of syncytial cells of $\mathrm{J} 2 \mathrm{ju}-$ veniles were lack of the central vacuole, gradually increased volume of the cytoplasm and proliferation of organelles (Fig. 16). Some of syncytial elements contained electrontranslucent flocculent material at the place formerly occupied by central vacuole. Numerous small irregularly shaped vacuoles and vesicles were scattered in this material. In other syncytial elements the central vacuole region was filled by the granular material not surrounded by a continuous membrane. In such cells dense cytoplasm was localized along syncytial wall. The numerous organelles: mitochondria, plastids containing starch grains, cisternae of endoplasmic reticulum present in both forms: rough and smooth, and Golgi Apparatuses were located mainly next to the wall of syncytial elements (Figs 17 and 19). The proliferation of syncytium was accompanied by changes in the cell walls of incorporated cells. First of all, the wall openings were progressively widened (Fig. 17). The edges of wall stubs surrounding a gap in the wall were rounded and through the existing opening the protoplast of adjacent cells had fused. In close vicinity of the enlarging wall openings the numerous organelles were located. In addition, the syncytial plasmalemma at places adjacent to xylem tracheary elements formed many invaginations, which gradu- 

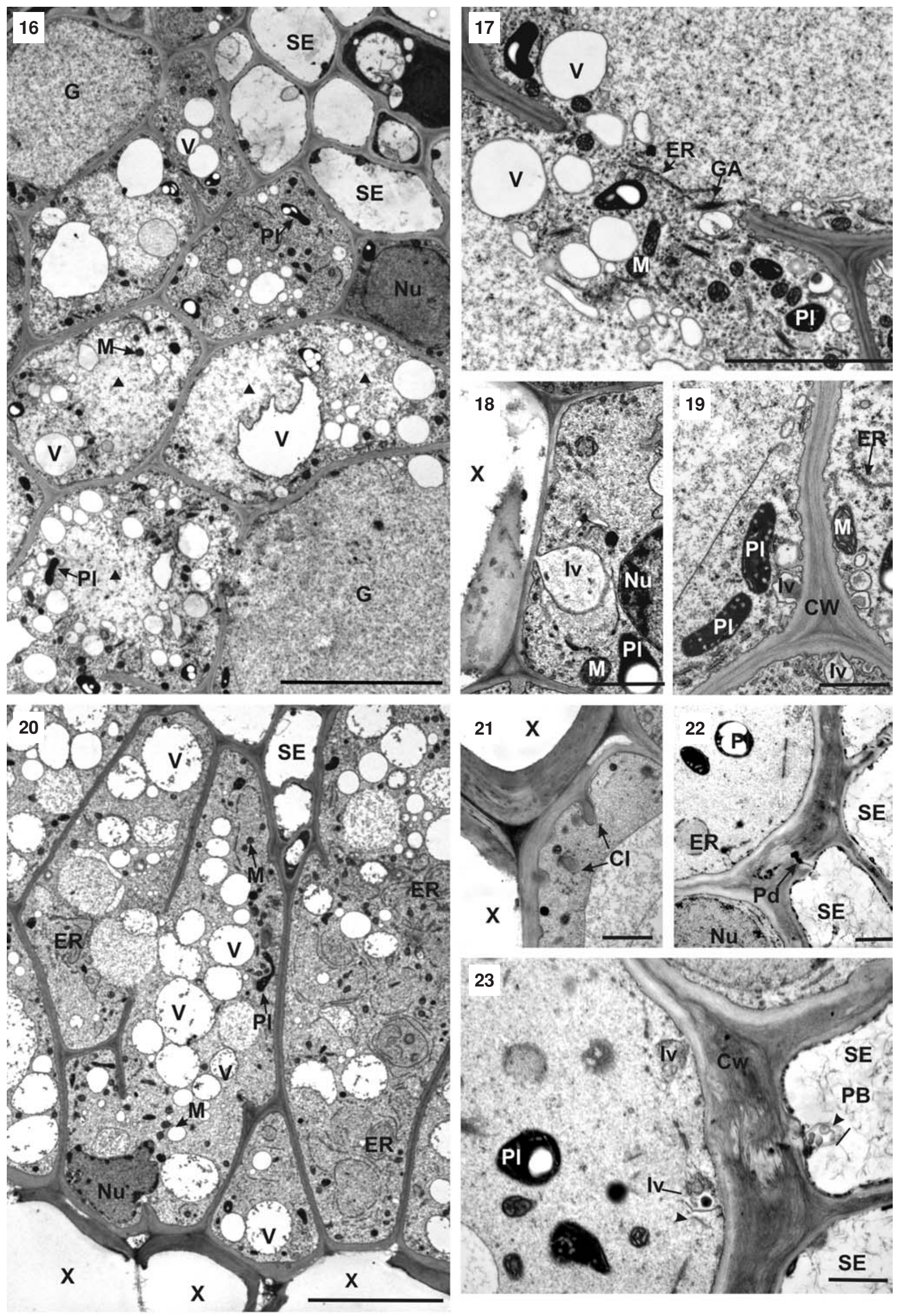
ally enlarged and contained fibrillar material (Fig. 18). Many plasmalemma invaginations filled with diverse material were also associated with walls of enlarging syncytial elements (Fig. 19). The smaller invaginations had homogenous content, while larger ones contained fibrillar material.

The ultrastructure of syncytial elements corresponding to J3 juveniles (10 dpi) was characterized by a more homogenous protoplast organization (Fig. 20). The syncytial elements were occupied by dense cytoplasm with areas filled with less condensed material not surrounded by any membrane or partially surrounded with fragments of a single membrane. In the syncytial protoplast numerous vacuoles were present. Some of them contained small amounts of fibrillar material. The endoplasmic reticulum proliferated and cisternae of smooth reticulum were regularly arranged in characteristic circular, concentric whorls (Fig. 20). The nuclei of cells incorporated into the syncytium were enlarged and acquired irregular ameboid shapes. Along the syncytial walls numerous mitochondria and elongated, cup-like shaped plastids were located. The wall openings were progressively widened. In addition wall ingrowths were exclusively formed at the syncytial wall abutting xylem tracheary elements (Fig. 21). At early stages of their formation they had a finger-like shape, were not branched and they were encircled with plasmallema. The syncytial wall bordering to other root cells was considerably thickened. The wall between sieve elements and syncytium seemed to lack of functional plasmodesmata, because the new layers of secondary wall were deposited also at places were plasmodesmic connection existed (Fig. 22). On the serial sections only non-continuous plasmodesmata starting at the side of sieve elements and blindly ended in the syncytial wall were occasionally found. The wall layers of the thickened wall appeared to be loosen locally as they contained electron translucent regions with regularly arranged fibrils. With such relaxed wall areas invaginations of cell membrane containing different material and paramural bodies were associated (Fig. 23).

\section{Localization of LeEXP A5 in nematode infected roots}

The specificity of the polyclonal anti-EXP A5 antibody was checked in the Western Blot analysis (data not shown). The temporal and spatial distribution pattern of expansin 5 protein was studied on semi-thin sections using immunofluorescent localization. In the roots containing young syncytia at 3 dpi (corresponding to the J2 stage) the fluorescent signal was observed in walls of enlarging syncytial elements (Fig. 24). There was no specific fluorescence in the walls of cortical cells surrounding developing syncytium. On sections of roots containing syncytia at $10 \mathrm{dpi}$ different expression pattern was observed (Fig. 25). The fluorescent signal was present only in the walls of distal syncytial elements. There was no labelling in the walls of cells surrounding expanding syncytium. After immunogold-labelling the gold particles were evenly distributed in the walls of young syncytia (at $3 \mathrm{dpi}$, data not shown) and in the walls of peripheral elements of syncytia at $10 \mathrm{dpi}$ (Fig. 27). There was no labelling at the edges of the syncytial walls bordering with cell wall opening (Fig. 28).

As the negative control in the immunolocalization experiments primary anti-EXP A5 antibody was replaced with preimmune serum. No signal was found on semi thin sections and ultra-thin sections subjected to this control immuno-labelling procedures (Figs 26 and 29, respectively).

\section{DISCUSSION}

\section{Anatomy and ultrastructure of syncytium}

The complex interactions between cyst nematode and it host results in the formation of syncytium, a type of organ providing nutrients for the developing nematode. Depending on host-parasite combination different cells are selected as the ISCs. The beet cyst nematode Heterodera schachtii usually induce syncytia in pericyclic or procambial cell abutting xylem tracheary elements in Arabidopsis thaliana roots (Golinowski et al. 1996), while Heterodera avenae usually selects the ISC from pericycle in wheat roots (Grymaszewska and Golinowski 1991). In soybean roots parasitized by Heterodera glycines syncytia are induced in cortical, pericycle or phloem parenchyma cells (Endo 1991). In this investigation it was observed that G. rostochiensis usually induces syncytia in the cortex. These observations agree with previous histological studies carried out on potato (Jones and Northcote 1972) and tomato (Sembdner 1963). Several reports indicate, that the differences in sites of syncytium induction are related to differences in the susceptibility of analyzed cultivars (Golinowski and Magnusson 1991; Melillo et al. 1990). It was also observed that type of cell selected as ISC correlates strictly with future sex of the associated juveniles (Golinowski et al. 1996; Sobczak et al. 1997). Although the selection of the ISC is crucial for successful plant-nematode interaction the molecular factors of mutual recognition between nematode and plant crucial for the selection of ISC have not been identified yet.

The existing plasmodesmata were shown to be initial sites for cell wall opening formation during syncytium induction in model A. thaliana plants infected with $H$. schachtii (Grundler et al. 1998). It seems that at early sta-

Figs 16-19. Ultrastructure of the syncytium at 3 days post induction (Figs 16-19) and at 10 days post induction (Figs 20-23).

Fig. 16. Fragment of syncytium. Central vacuolar region is replaced with electrontranslucent material (triangles) or with granular material (G). M - mitochondrion; $\mathrm{Nu}$ - nucleus; Pl - plastid; SE - sieve elements; V - small vacuoles. Bar $10 \mu \mathrm{m}$. Fig. 17. Close to the enlarged cell wall opening numerous plastids (Pl), mitochondria (M), dictyosomes (GA) are present. ER - endoplasmic reticulum; V - vacuole. Bar 5 um. Fig. 18. The part of the syncytium abutting xylem tracheary element (X). Nu - nucleus; Pl - plastids; M - mitochondrion; Iv - membrane invaginations. Bar $1 \mu$ m. Fig. 19. Fragment of cell wall (CW) of syncytial elements. With the syncytial walls numerous membrane invaginations are associated (Iv). Close to syncytial wall plastids (Pl), mitochondria (M) and cisteranae of endoplasmic reticulum are scattered (ER). Bar $1 \mu \mathrm{m}$. Fig. 20. Fragment of the syncytium located in the vascular cylinder between xylem tracheary elements (X) and sieve elements (SE). In the syncytial cytoplasm many vacuoles are present (V), the cistarnae of smooth endoplasmic reticulum (ER) form characteristic concentric whorls, nuclei $(\mathrm{Nu})$ acquire ameboid shape, plastids (Pl) and mitochondria (M) are located mainly close to the syncytial wall. Bar $10 \mu \mathrm{m}$. Fig. 21. The interface between syncytium and xylem (X). Characteristic cell wall ingrowths (CI) are formed on the syncytial wall. Bar $2 \mu \mathrm{m}$. Fig. 22. The interface between syncytium and phloem. Obstructed plasmodesmata (Pd) is visible in the wall, starting at the side of sieve element (SE). Pl - plastid; ER - endoplasmic reticulum; Nu - nuclei. Bar $1 \mu \mathrm{m}$. Fig. 23. Cell wall invaginations and paramural bodies associated with cell wall between syncytium and phloem (SE). CW - cell wall; Iv - membrane invaginations; PB - paramural body; Pl - plastid. Bar 1 um. 

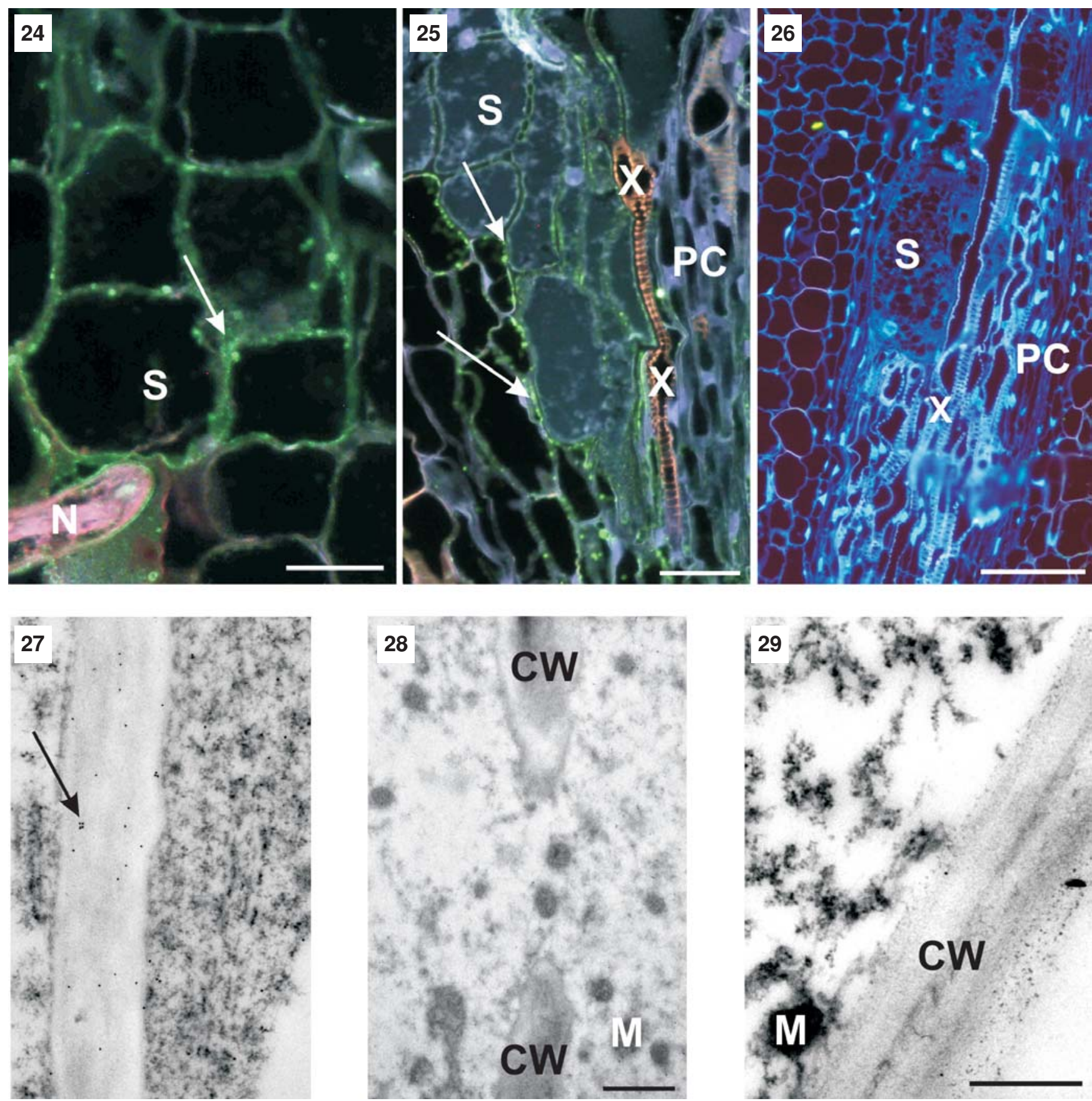

Figs 24-29. Localization of LeEXP A5 in nematode infected roots using immunofluorescent-labelling (Figs 24-26) and immunogold-labelling (Figs 27-29).

Fig. 24. The fluorescent signal (arrow) is present in the walls of all syncytial elements in 3 dpi syncytium (S). $\mathrm{N}$ - nematode. Bar $30 \mu \mathrm{m}$. Fig. 25. The fluorescent signal (arrows) is present in the walls of distal syncytial elements derived from parenchymatic vascular cylinder cells in 10 dpi syncytium (S). PC - parenchyma cells not incorporated to the syncytium, X - xylem tracheary elements. Bar $50 \mu \mathrm{m}$. Fig. 26. Control labelling with pre-immune serum carried out of section of 10 dpi syncytium (S). PC - parenchyma cells not incorporated to the syncytium; S - syncytium; X - xylem tracheary elements. Bar $50 \mu \mathrm{m}$. Fig. 27. The gold particles (arrow) indicating presence of LeEXP A5 are equally scattered in the wall of distal syncytial element (CW) (10 dpi). Bar $0.5 \mu \mathrm{m}$. Fig. 28. The gold particles were not observed at the site of wall opening formation. $\mathrm{CW}-$ fragment of cell walls at the site of wall opening, $\mathrm{M}$ - mitochondrion. Bar $0.5 \mu \mathrm{m}$. Fig. 29. Control reaction with pre-immune serum performed on ultra-thin sections. Lack of gold labelling confirms the specificity of the immunolocalization method. $\mathrm{CW}$ - cell wall of syncytial element; $\mathrm{M}$ - mitochondrion. Bar $0.5 \mu \mathrm{m}$.

ges of syncytium development in tomato roots infected with $G$. rostochiensis, the wall openings are also formed in the same way, by gradual widening of existing plasmodesmic connections.

The presented results concerning cell alterations prior to their incorporation into developing syncytia: cell expansion, proliferation of organelles and loss of central vacuole are generally consistent with results previously described by other authors (Jones and Northcote 1972; Golinowski et al. 1996; Golinowski and Magnusson 1991; Melillo et al. 1990). Characteristic ultrastructural changes are supposed to be adaptations of syncytial elements for intensive processes of synthesis and transports that enable them to function as an effective structure delivering nutrients for the nematode. The observed enlargements of nuclei in syncytial elements are probably a result of endoreduplication of DNA (Niebel et al. 1996). The proliferation of smooth endoplasmic reticulum occuring in latter developmental sta- 
ges seems to be essential for compatible plant-nematode interaction. In many cases, syncytia induced in resistant plants contain only a weakly developed system of endoplasmic reticulum (Grymaszewska and Golinowski 1998; Sobczak et al. 2005). Golinowski et al. (1996) proposed that smooth endoplasmic reticulum being the place of synthesis of lipids plays an essential role in nematode nutrition and proper development. According to observation, that cysternae of endoplasmic reticulum form aggregations at site of stylet insertion and that they are connected with feeding tubes (Endo 1991; Sobczak et al. 1999), it has been postulated that system of endoplasmic reticulum may establish also a unique network which transports synthesized substances directly to the developing nematode (Hussey et al. 1994). The function of numerous wall invaginations containing homogenous material or paramural bodies associated with syncytial wall is still a matter of speculation. The probability that they are artifacts has been excluded, because these structures were repetitively observed in the same regions at the same developmental stages of syncytia (Golinowski et al. 1996). The paramural bodies have been implicated in the processes such as cell wall synthesis during syncytial wall thickening (Rice et al. 1985) or vesicular transport (Tanchak and Fowke 1987; Kronestedt-Robards and Robards 1991).

Root regions just above root tips and primordia of lateral roots are known as natural plant sink tissues, which symplastically import photoassimilates from phloem to maintain growth and development of the root system (Oparka et al. 1994). Böckenhoff et al. (1996) using fluorescent dyes and confocal microscopy revealed that solutes transported via phloem are effectively unloaded into the syncytia. The localization of syncytium induction site within the root elongation zone just behind the root tip ensures that syncytia induced there will be efficiently and quickly supplied with nutrients that will be further withdrawn by juveniles. The anatomical and ultrastructural features of syncytium suggest that developing syncytium competes with non affected root tip cells for photoassimilates. In tomato roots, G. rostochiensis usually chooses cortical or pericyclic cells localized next to the phloem bundle for syncytium induction and syncytia relatively quickly reach phloem and xylem (2-3 dpi). As syncytium develops by incorporation of new pericyclic and vascular parenchyma cells the phloem bundle is entrapped among syncytial elements what prevents the leakage of transported assimilates into other root cells and ensures large surface at interface between phloem and syncytium. In a model interaction between $A$. thaliana and $H$. schachtii the differentiation of new phloem elements around developing syncytium was even observed (Golinowski et al. 1996; Hoth et al. 2005). However the way of solutes transport from phloem to syncytium still remains enigmatic, because there are no direct ultrastructural evidences for neither apoplastic nor symplastic way of phloem unloading into nematode feeding site. First of all, cell wall ingrowths were observed only at the syncytial wall adjoining xylem tracheary elements but there were never observed at walls abutting sieve elements what could intensify short-distance apoplastic transport. It was postulated that syncytia are symplastically isolated and that observed plasmodesmata are non-functional because they were occluded by cell wall deposits (Grundler et al. 1998). However Hoth et al. (2005), using transgenic Arabidopsis plants expressing GFP fusion constructs under companion cell specific promoter (AtSUC2), demonstrated that transport of macromolecules between phloem and syncytia occurs and concluded that plasmodesmatal connections exist between phloem and syncytia. Recent studies of Hofmann and Grundler (2006) provided additional support for postulated symplastic connections between syncytia and phloem. However, electron microscope observations presented in this paper do not support this hypothesis as at phloem-syncytium interface only plasmodesmata, which seems to be apparently non-functional, were observed on serial sections. The cell wall of syncytial elements is considerably thickened including fragments of syncytial walls neighbouring with phloem elements. The new wall layers were synthesized and deposited also at places of plasmodesmata and as a result the syncytium seems to be also devoid of pre-existing symplastic connections. In addition formation of new secondary plasmodesmata between syncytium and phloem have never been observed and described. The third and the most intriguing mechanism of phloem unloading remained is endocytosis (Oparka and Prior 1998) and this way of solute translocation from phloem into the syncytia should also be taken into consideration.

The presented results indicate that the extent of syncytium proliferation depends not only on the type of ISC selected but also in which root zone it is induced. The cortical or pericyclic cells in root hair zone just above the root tip seem to be the best place for syncytium induction. This place is a well-established nutrient sink, but also because it contains cells that seem to be easily subjected to dedifferentiation. Contrary, induction of syncytium in the root being in the stage of secondary growth resulted in poorly developed syncytium consisting of weakly hypertrophied cells. In this part of the root system phloem unloading occurs selectively at lateral root primordia. Moreover, cells of roots being in the stage of secondary thickening are less susceptible to syncytium induction.

\section{Function of EXP A5 during syncytium formation}

Previously it was shown that the expression pattern of Le EXP A5 at both transcript and protein levels is strongly correlated with the process of syncytium expansion (Fudali et al. 2004). It was also proposed that EXP A5 mediates cell wall expansion during hypertrophy of syncytial elements. In this paper, we presented additional results of immunolocalization and observation of syncytium anatomy that support this hypothesis. At the onset of syncytium development all cells incorporated into syncytium hypertrophied, while in later stages the hypertrophy of syncytial elements occurred only in the recently incorporated cells derived from vascular cylinder. Notably, it was observed that extend of hypertrophy of recently incorporated cells in distal part of syncytium is higher (approximately 5 times) than extend of hypertrophy of the "cortex bridge" cells (approximately 1.5-2.0 times). Immunofluorescent-labelling revealed that distribution pattern of expansin 5 protein follows the expansion in syncytia. The fluorescent signal was observed in all syncytial walls of young syncytia (3 dpi) while in the older syncytia (10 dpi) high amounts of investigated protein were exclusively detected in the peripheral part of syncytium that was derived from vascular parenchyma. The additional immunogold-localization experiments excluded that expansin 5 may contribute to cell wall 
opening formation, as gold particles were never observed at the place where wall dissolution occurred. The presented immunolocalization results agree with previous Nothern Blot experiments which demonstrated that expansin 5 is expressed abundantly in tomato fruit at stages characterized by rapid cell expansion (Brummell et al. 1999). Interestingly, it was demonstrated recently that expansin 5 is also up-regulated in tomato roots infected with root-knot nematode Meloidogyne javanica (Gal et al. 2006). Root-knot nematode induces in infected roots a different type of feeding organs called "giant cells". Silencing of LeEXP A5 expression leaded to the hampered development of root knot nematode, indicating that plant expansin gene is prerequisite for successful parasitism. Cell hypertrophy accompanying syncytium development is one of the determinants of successful nematode development, as syncytia induced in resistant plants are usually less hypertrophied than the ones induced in compatible host (Grymaszewska and Golinowski 1998; Rice et al. 1985). Numerical analysis performed by Golinowski et al. (1996) revealed that increased volume of syncytia is mainly due to the hypertrophy of incorporated cells rather than their number. Thus, LeEXP A5 gene seems to be a good target for silencing, when constructing plants resistant to cyst nematode.

It would be interesting to check in the future which molecular factors are responsible for activation of expansin 5 during plant-parasitic nematode interaction. There are at least three reasons, why auxins seem to be a good candidate. First of all, previous experiments indicated that expansin expression is regulated by phytohormones including auxin (Catala et al. 2000). Secondly, expansins have a pH optimum for cell-wall extension of about 4 and auxins are implicated in cell wall acidification during cell growth (McQueen-Mason et al. 1992; Rayle and Cleland 1992). Thirdly, syncytium induction and development is accompanied by local increase in auxin concentration and it was suggested that auxin may promote changes occurring in cells during its fusion with the expanding syncytium (Goverse et al. 2000; Karczmarek et al. 2004).

\section{ACKNOWLEDGEMENTS}

This research was supported by Doctoral Grant of Polish Ministry of Education and Science (2 P06R 03028 ) and $5^{\text {th }}$ Framework Programme of the European Union "NONEMA" (QLK-CT-1999-01501).

\section{LITERATURE CITED}

BÖCKENHOFF A., PRIOR D.A.M., GRUNDLER F.M.W., OPARKA K.J. 1996. Induction of phloem unloading in Arabidopsis thaliana roots by the parasitic nematode Heterodera schachtii. Plant Physiol. 112: 1421-1427.

BRUMMELL D.A., HARPSTER M.H., DUNSMUIR P. 1999. Differential expression of expansin gene family members during growth and ripening of tomato fruit. Plant Mol. Biol. 39: 161-169.

CATALA C., ROSE J.K.C., BENNETT A.B. 2000. Auxin regulated genes encoding cell wall-modifying proteins are expressed during early tomato fruit growth. Plant Physiol. 122: 527-534.

ENDO B.Y. 1991. Ultrastructure of initial responses of susceptible and resistant soybean roots to infection by Heterodera glycines. Rev. Nematol. 14: 73-94.
FLEMING A.J., CADERAS D., WEHRLI E., MCQUEEN-MASON S., KUHLEMEIER C. 1999. Analysis of expansin-induced morphogenesis on the apical meristem of tomato. Planta 208: 166-174.

FUDALI S., SOBCZAK M., JANAKOWSKI S., GOLINOWSKI W. 2004. Expansin gene LeEXP5 is specifically up-regulated during syncytium induction and development in tomato roots Lycopersicon esculetum infected with potato cyst nematode Globodera rostochiensis. Acta Physiol. Plant. 26: 270.

GAL T.Z., AUSSENBERG E.R., BURDMAN S., KAPULNIK Y., KOLTAI H. 2006. Expression of a plant expansin is involved in the establishment of root knot nematode parasitism in tomato. Planta 224: 155-162.

GHEYSEN G., FENOLL C. 2002. Gene expression in nematode feeding sites. Annu. Rev. Phytopathol. 40: 191-219.

GOLINOWSKI W., GRUNDLER F.M.W., SOBCZAK M. 1996. Changes in the structure of Arabidopsis thaliana during female development of the plant parasitic nematode Heterodera schachtii. Protoplasma 194: 103-116.

GOLINOWSKI W., MAGNUSSON C. 1991. Tissue response induced by Heterodera schachtii (Nematoda) in susceptible and resistant white mustard cultivars. Can. J. Bot. 69: 53-62.

GOVERSE A., OVERMARS H., ENGELBERTINK J., SCHOTS A., BAKKER J., HELDER J. 2000. Both induction and morphogenesis of cyst nematode feeding cells are mediated by auxin. MPMI 13: 1121-1129.

GRUNDLER F.M.W., SOBCZAK M., GOLINOWSKI W. 1998. Formation of wall openings in root cells of Arabidopsis thaliana following infection by the plant-parasitic nematode Heterodera schachtii. Eur. J. Plant Pathol. 104: 544-551.

GRYMASZEWSKA G., GOLINOWSKI W. 1991. Structure of syncytia induced by Heterodera avenae Woll. in roots of susceptible and resistant wheat (Triticum aestivum L.) J. Phytopathol. 133: 307-319.

GRYMASZEWSKA G., GOLINOWSKI W. 1998. Structure of syncytia induced by Heterodera schachtii Schmidt in roots of susceptible and resistant radish (Raphanus sativus L. var. oleiformis). Acta Soc. Bot. Pol. 67: 207-216.

HAYDOCK P.P.J., EVANS K. 1998. Management of potato cyst nematodes in the UK: an integrated approach? Autlook Agr. 27: $253-260$

HOFMANN J., GRUNDLER F.M.W. 2006. Females and males of root-parasitic cyst nematodes induce different symplastic connections between their syncytial feeding cells and the phloem in Arabidopsis thaliana. Plant Physiol. Biochem. 44: 430-433.

HOTH S., SCHNEIDEREIT A., LAUTERBACH C., SCHOLZSTARKE J., SAUER N. 2005. Nematode infection triggers the de novo formation of unloading phloem that allows macromolecular trafficking of green fluorescent protein into syncytia. Plant Physiol: 138: 383-392.

HUSSEY R.S., DAVIS E.L., RAY C. 1994. Meloidogyne stylet secretions. In: Advances in molecular plant nematology. Lamberti F., De Giorgi C., Bird McK (eds Plenum Press, New York, NATO ASI series A, Vol. 268, pp 233-247.

JONES M.G.K. 1981. The development and function of plant cells modified by endoparasitic nematodes. In: Plant Parasitic Nematodes Vol. 3. Zuckerman and Rohde (eds) New York: Academic Press, pp 255-279.

JONES M.G.K., NORTHCOTE D.H. 1972. Nematode-induced syncytium - a multinucleate transfer cell. J. Cell Sci. 10: 789$-809$.

KARCZMAREK A., OVERMARS H., HELDER J., GOVERSE A. 2004. Feeding cell development by cyst and root-knot nematodes involves a similar early, local and transient activation of a specific auxin-inducible promoter element. Mol. Plant Pathol. 5: 343-346.

KRONESTEDT-ROBARDS E., ROBARDS A.W. 1991. Exocytosis in gland cells. In: Endocytosis, exocytosis and vesicle traffic in plants. Hawes C.R., Coleman J.O.D., Evans D.E. 
(eds). Cambridge Univesity Press, Cambridge, Seminar Series, no 45, pp 199-232.

MCQUEEN-MASON S.J., COSGROVE D.J. 1994. Disruption of hydrogen-bonding between plant-cell wall polymers by proteins that induce wall extension. PNAS USA 91: 6574-6578.

MCQUEEN-MASON S.J., DURACHKO D.M., COSGROVE D.J. 1992. Two endogenous proteins that induce cell-wall extension in plants. Plant Cell 4: 1425-1433.

MELILLO M.T., BLEVE-ZACHEO T., ZACHEO G. 1990. Ultrastructural response of potato roots susceptible to cyst nematode Globodera pallida pathotype Pa 3. Rev. Nématol. 13: 17-28.

NIEBEL A., de ALMEIDA ENGLER J., HEMERLY A., FERREIRA P., INZÉ D., VAN MONTAGU M., GHEYSEN G. 1996. Induction of $c d c 2 a$ and cyclAt expression in Arabidopsis thaliana during early phases of nematode induced feeding cell formation. Plant J. 10: 1037-1043.

OPARKA K.J., DUCKETT C.M., PRIOR D.A.M., FISHER D.B. 1994. Real-time imaging of phloem unloading in the root tip of Arabidopsis. Plant J. 6: 759-766.

OPARKA K.J., PRIOR D.A.M. 1998. Movement of Lucifer Yellow $\mathrm{CH}$ in potato tuber storage tissues: a comparison of symplastic and apoplastic transport. Planta 176: 533-540.

RAYLE D.L., CLELAND R.E. 1992. The acid growth theory of auxin-induced cell elongation is alive and well. Plant Physiol. 99: 1271-1274

RICE S.L., LEADBEATER B.S.C., STONE A.R. 1985. Changes in cell structure in roots of resistant potatoes parasitized by potato cyst nematodes. 1. Potatoes with resistance gene H1 deri- ved from Solanum tuberosum ssp. andigena. Physiol. Plant. Pathol. 27: 219-234.

ROSE J.K.C., LEE H., BENNETT A.B. 1997. Expression of a divergent expansin gene is fruit specific and ripening-regulated. PNAS USA 94: 5955-5960.

SEMBDNER G. 1963. Anatomie der Heterodera-rostochiensisGallen an Tomatenwurzeln. Nematologica 9: 55-64.

SOBCZAK M., AVROVA A., JUPOWICZ J., PHILLIPS M.S., ERNST K., KUMAR A. 2005. Characterization of susceptibility and resistance responses to potato cyst nematode (Globodera spp.) infection of tomato lines in the absence and presence of the broad-spectrum nematode resistance Hero gene. MPMI 18: 158-168.

SOBCZAK M., GOLINOWSKI W., GRUNDLER F.M.W. 1997. Changes in the structure of Arabidopsis thaliana roots induced during development of males of plant parasitic nematode $\mathrm{He}$ terodera schachtii. Eur. J. Plant Pathol. 103: 113-124.

SOBCZAK M., GOLINOWSKI W., GRUNDLER F.M.W. 1999. Ultrastructure of feeding plugs and feeding tubes formed by Heterodera schachtii. Nematology 1: 363-374.

TANCHAK M.A., FOWKE L.C. 1987. The morphology of the multivesicular bodies in soybean protoplasts and their role in endocytosis. Protoplasma 138: 173-182.

VANHOLME B., DE MEUTTER J., TYTGAT T., VAN MONTAGU M., COOMANS A., GHEYSEN G. 2004. Secretions of plant-parasitic nematodes: a molecular update. Gene 332: 13-27.

WYSS U. 1992. Observation of the feeding behaviour of Heterodera schachtii throughout development, including events during moulting. Fundam. Appl. Nematol. 15: 75-89. 